\section{Conversações sobre a "boa morte": o debate bioético acerca da eutanásia}

\author{
Conversations on the "good death": \\ the bioethical debate on euthanasia
}

Rodrigo Siqueira-Batista 1,2 Fermin Roland Schramm 2,3

\footnotetext{
1 Fundação Educacional Serra dos Órgãos, Teresópolis, Brasil.

2 Escola Nacional de Saúde Pública, Fundação Oswaldo Cruz, Rio de Janeiro, Brasil.

3 Instituto Nacional de

Câncer, Rio de Janeiro, Brasil.

Correspondência

R. Siqueira-Batista Núcleo de Estudos em Filosofia e Saúde, Fundação Educacional Serra dos Órgãos. Av. Alberto Torres 111, Teresópolis, RJ 25964-000, Brasil. anaximandro@hotmail.com
}

\begin{abstract}
Despite extensive current debate on euthanasia, many open and apparently unsolvable issues persist, awaiting a better conceptual treatment. The area includes "prejudices and fundamentalisms" in relation to the theme, still viewed as taboo by a major share of society, specifically in the case of Brazil, while semantic imprecision in the term and argumentative tensions surround the issue, focusing on the principles of sacredness of life, quality of life, and autonomy and the so-called "slippery slope" argument. The purpose of the current essay is thus to serve as a sphere of inquiry concerning euthanasia, moving from historical antecedents towards a better solution to the problem and the demarcation of necessary future perspectives for enhanced understanding of the issue.
\end{abstract}

Euthanasia; Bioethics; Public Health

\section{Introdução}

A bioética, enquanto disciplina que se refere à moralidade dos atos humanos que podem alterar, de forma significativa e irreversível, os sistemas autopoiéticos, também irreversíveis, representados pelos seres vivos 1, vem se debruçando, em particular, sobre um amplo leque de problemas relativos ao processo vida-morte. Neste horizonte se inscrevem as questões do nascer e do morrer, consideradas naturais até meados do século passado, as quais sofreram uma decisiva modificação nos últimos cinqüenta anos, inscrita mutatis mutandis na própria tensão arcaica entre $\phi v \sigma ı \varsigma$ (physis) e $\tau \varepsilon \chi v \eta$ (téchne) - colocada pelos pensadores gregos e retomada, sucessivamente, na tradição filosófica do Ocidente 2,3 , reinterpretando-a à luz dos novos desafios instados pelas profundas transformações ocorridas historicamente neste processo. Assim, já não se pode mais falar impunemente, quando nos referirmos aos processos do viver e do morrer, de uma natureza em si - conceito de fato bastante esvaziado desde a clara distinção kantiana entre númeno e fenômeno 4 - sendo mais apropriado falar de uma condição do Homo sapiens definível por uma dupla dimensão: bioecológica ou "primeira natureza", propriamente natural; e técnicolingüística ou "segunda natureza”, engendrada no plano simbólico - as quais interagem e se condicionam fluida e mutuamente 5 . 
Em particular, na interseção e na dialética entre estas duas naturezas, antecipadas pelos termos gregos physis e téchne, se define boa parte do debate contemporâneo sobre o processo de morrer. Assim, pois, não cabe tão somente se interrogar sobre a morte enquanto tal - em última análise, um problema de ordem científica, com implicações próprias, como nas decisões acerca dos transplantes de órgãos 6,7 -, devendo, outrossim, desviar o âmago do movimento - o turbilhão a partir do qual floresce o passamento - para sua mais lídima tessitura, de ordem existencial e filosófica: a finitude 8,9 , o que estabelece uma atitude a ser situada em um lugar algo afim às formulações deleuzianas: “(...) a filosofia acreditava ter acabado com o problema das origens. Não se tratava mais de partir nem de chegar. A questão era antes: o que se passa 'entre'? E é exatamente a mesma coisa para os movimentos físicos" 10 (p. 151, grifo nosso).

Tal é o primeiro recorte relevante: o que realmente importa é o que se passa entre o estar vivo e o estar morto, isto é, de como conceber o viver e, mais ainda, dos problemas éticos, e especificamente bioéticos, que se colocam nesta passagem entre a vida e a morte - os quais se acham completamente imbricados em conceitos como sofrimento e qualidade (ou precariedade) de vida 11 -, mormente se entram em cena os referenciais delineados pela tecnociência. Dentre as várias questões cruciais que se inserem neste panorama mais amplo da bioética do fim da vida - ou da finitude -, está a eutanásia, práxis que vem sendo entendida, desde a antigüidade 12, em seu sentido literal: "boa morte ( $\varepsilon v=a d v$. bem // regular, justamente // com bondade, com benevolência // felizmente; $\theta \alpha v \alpha \tau o s=$ morte), ou seja, um passamento sem dor e sem sofrimento" 13 (p. 858). O desvio que transformou, e desvirtuou, a eutanásia em política pública ocorreu no século XX - acabando por cristalizar uma conotação marcadamente negativa -, por ocasião do Terceiro Reich, quando a palavra eutanásia foi, de fato, utilizada para referirse a práticas que não tinham nada a ver com a morte sem sofrimento, devendo-se, a rigor utilizar seu antônimo para indicar tais práticas. Com efeito, em outubro de 1939, o Estado Nazista promulgou a Aktion T4 - um programa financiado pelo governo que visava a eliminação de vidas que não valiam a pena ser vividas (lebensunwerte Leben) - que levou à morte mais de 100 mil pessoas - ciganos, negros e judeus nos seus quase dois anos de funcionamento, antes de ser extinta em agosto de 194314.

No período de profundo mal-estar do imediato pós-guerra - em decorrência da sensação de desamparo imputada pelos horrores do con- flito e da desesperança em relação à recorrência da barbárie -, manifestou-se uma grande repulsa pelo tema da eutanásia, num claro fenômeno de recalque. Entretanto, o reconhecimento de que o programa nazista de "eutanásia” não era, em absoluto, uma autêntica eutanásia, isto é, uma Gnadentod, ou "morte piedosa” - afinal, não se destinava a prover uma boa morte para seres humanos que levavam uma vida infeliz 15 -, acabou por proporcionar uma retomada das discussões em torno do tema, alavancada por uma nova conjuntura marcada por substanciais transformações: (1) modificações nas coordenadas sociais, especialmente nas décadas de 60 e 70, com a retomada do debate ético e filosófico dirigido às questões de âmbito prático, no bojo do qual se deu o "nascimento" da bioética 16,17; (2) as indagações relacionadas aos avanços das técnicas de manutenção da vida e prolongamento da sobrevida, capazes de sustentar enfermos com condições de extrema gravidade - por vezes, inequivocamente fatais - mesmo sem qualquer perspectiva de recuperação 5; (3) a ocorrência de várias "situações clínicas" que levantaram incontornáveis questões sobre a moralidade da eutanásia e do suicídio assistido - casos Karen Ann Quinlan (1975-1976), Spring (1977-1980), Diane-Quill (1996), Ramón San Pedro (1998), Jack Kevorkian, o "doutor morte" (anos 90) e Vincent Humbert (2003) 18 - somente para mencionar as mais notórias 18,19,20,21,22; (4) o progressivo envelhecimento populacional - como observado no Brasil - permitindo que um maior número de pessoas cheguem à senectude, tornandose mais suscetíveis às moléstias crônicas e degenerativas e, por conseguinte, a um processo de morrer mais "prolongado" e sujeito ao padecimento, com sérias implicações relativas à alocação de recursos em saúde pública 9,23,24; (5) a aprovação de leis autorizando a eutanásia em vários países do mundo, como na Austrália (de julho de 1996 a março de 1997), na Holanda (abril de 2001), na Suíça e na Bélgica (maio de 2002) 25,26.

Ainda que a eutanásia venha merecendo grande atenção na comunidade mundial, o debate está muito longe do desejável na sociedade brasileira. Pelo fato de ser ainda considerada crime no Brasil - como o disposto no artigo 121 do Código Penal 27,28 - tem sido mantido um nefasto pacto de silêncio nas unidades de assistência à saúde, nas quais a decisão por interromper - ou não - a terapêutica acaba por ser tomada às escuras, por profissionais habitualmente sem qualquer preparação para isto, e pior, muitas vezes à revelia dos familiares e do próprio enfermo 29,30,31. Discutir e ponderar 
sobre a moralidade da eutanásia, demarcandose adequadamente os conceitos e enfocando-se os argumentos favoráveis e contrários à sua realização, torna-se premissa crucial para um mais amplo exercício da cidadania - ao menos nas sociedades laicas e plurais contemporâneas -, bem como para a formação e atuação laboral em saúde. Deste modo, delimitar o estado atual da arte em relação ao debate bioético da eutanásia é, assim, o escopo do presente artigo.

\section{Conceitos fundamentais: em busca de rigor}

A delimitação lexical dos termos referentes à bioética do fim da vida está longe de ser ideal. Em verdade, há uma grande polissemia do vocábulo eutanásia, gerando inúmeros equívocos, o que se explica, em grande medida, pela própria "biografia" da palavra - longa, conflituosa e sujeita a gigantescas variações culturais 32,33. Em conseqüência da herança nazista anteriormente comentada, não é incomum o uso antifrástico da palavra eutanásia, atrelando-a a idéias como homicídio, suicídio influenciado ou genocídio, o que, em última análise, indica a pouca clareza e isenção para discuti-la, o que também engendra, não raramente, posicionamentos passionais, categóricos e dogmáticos 26,33.

Retomando as origens filológicas, Littré definiu a eutanásia como boa morte, morte suave e sem sofrimento 34 . Em termos mais contemporâneos, tratar-se-ia de uma antecipação voluntária do passamento, imbuída por um télos humanitário - sobretudo para a pessoa, mas também para a coletividade à qual pertence o moribundo - dirigido à suspensão de um sofrimento insuportável. Com base nesta colocação, pode-se estabelecer que a eutanásia seria melhor entendida como "o emprego ou abstenção de procedimentos que permitem apressar ou provocar o óbito de um doente incurável, a fim de livrá-lo dos extremos sofrimentos que o assaltam" 33 (p. 43, grifo nosso).

Deste modo, o âmago de um conceito como aquele de eutanásia deverá pressupor, necessariamente, a interrupção do processo de morrer - uma vez que o detentor da existência estará no curso de uma moléstia incurável, à luz dos conhecimentos médicos de um dado tempo - eximindo o moribundo de atravessar um martírio de dor e desespero, o que caracterizaria, de um modo ou de outro, uma existência prima facie sem sentido e considerada inútil, pelo menos para quem não está disposto a fazer do "calvário" um meio para dar sentido à sua vida.
Outro ponto da maior relevância é destacar a existência de uma série de situações distintas agrupadas sob o conceito genérico de eutanásia. Tal situação implica a necessidade de se distinguir as diferentes idéias e práticas metaforizadas pelo vocábulo em questão, o que tem sido um dos grandes esforços nas discussões hodiernas 33. Atualmente, as modalidades mais úteis para classificação da eutanásia basear-seiam no ato em si e no consentimento do enfermo. Deste modo, têm-se:

\section{- A distinção quanto ao ato 35}

(a) Eutanásia ativa - ato deliberado de provocar a morte sem sofrimento do paciente, por fins humanitários (por exemplo, utilizando uma injeção letal);

(b) Eutanásia passiva - quando a morte ocorre por omissão proposital em se iniciar uma ação médica que garantiria a perpetuação da sobrevida (por exemplo, deixar de se iniciar aminas vasoativas no caso de choque não responsivo à reposição volêmica);

(c) Eutanásia de duplo efeito - nos casos em que a morte é acelerada como conseqüência de ações médicas não visando ao êxito letal, mas sim, ao alívio do sofrimento de um paciente (por exemplo, emprego de morfina para controle da dor, gerando, secundariamente, depressão respiratória e óbito).

\section{- A distinção quanto ao consentimento do enfermo 35}

(a) Eutanásia voluntária - em resposta à vontade expressa do doente - o que seria um sinônimo do suicídio assistido;

(b) Eutanásia involuntária - quando o ato é realizado contra a vontade do enfermo, o que, em linhas gerais, pode ser igualado ao "homicídio"; todavia, a concepção de Kuhse 36 (p. 407) é algo distinta, caracterizando a eutanásia involuntária como aquela "que se pratica a uma pessoa que havia sido capaz de outorgar ou não o consentimento à sua própria morte, mas não o fez, seja por não ter sido solicitado, seja por ter rechaçado a solicitação, devido ao desejo de seguir vivendo";

(c) Eutanásia não voluntária - quando a vida é abreviada sem que se conheça a vontade do paciente.

Do ponto de vista da bioética, podem ser construídos argumentos distintos para as diferentes categorias de eutanásia relativas ao ato em si, havendo aqueles que condenam peremptoriamente a eutanásia ativa, mas "aceitam" a eutanásia passiva - por exemplo, julgando legí- 
timo que um enfermo que se negue a passar por medidas terapêuticas extraordinárias, ou seja, recuse a distanásia 11 - ou que, em decorrência de uma determinada modalidade terapêutica, acabe por sobrevir o óbito - no caso, eutanásia de duplo efeito 33,37. Todavia, no que se refere ao consentimento do enfermo, há justificativa moral para a eutanásia voluntária 15,38 e, eventualmente, para a não voluntária 39 , mas não para a involuntária - de fato um ato criminoso, na medida em que representa um desrespeito à vontade do paciente!

Para tornar mais diáfano o campo conceitual da bioética do fim da vida, são ainda pertinentes alguns comentários acerca da terminologia, no que se refere à conceituação do suicídio assistido, da distanásia e das assim chamadas ortotanásia e mistanásia.

O suicídio assistido ocorre quando uma pessoa solicita o auxílio de outra para alcançar o óbito, caso não seja capaz de tornar fato sua disposição de morrer 40,41. Neste caso, o enfermo está, em princípio, sempre consciente - manifestando sua opção pela morte -, enquanto na eutanásia nem sempre o doente encontra-se cônscio - por exemplo, na situação em que um paciente terminal e em coma está sendo mantido vivo por um ventilador mecânico, o qual é desligado, ocasionando a morte. Os casos mais conhecidos foram praticados pelo médico patologista estadunidense Jack Kevorkian, coadjuvante de vários suicídios assistidos, que levaram à sua condenação e prisão em seu país.

Contraposta à eutanásia e ao suicídio assistido tem-se a distanásia - também identificada pars pro toto com a denominada obstinação terapêutica - a qual tem como interfaces tanto a aplicação de novas tecnologias à medicina capazes de manter as funções biológicas, com amplas possibilidades para salvar grande número de vidas - quanto o arcaico desejo humano de superar a morte 9,42. Etimologicamente o termo distanásia contém a idéia de "dupla morte $(\delta \mathrm{s}=$ dificuldade, privação $/ / \delta\llcorner\sigma \theta \alpha v \eta \varsigma=a d-$ jetivo: que morre duas vezes; no latim, dis dá idéia de separação e negação)" 13 (p. 858), tendo sido inicialmente proposto por Morache, em 1904. Atualmente é compreendida como manutenção da vida por meio de tratamentos desproporcionais, levando a um processo de morrer prolongado e com sofrimento físico ou psicológico, isto é, de um aprofundamento das características que tornam, de fato, a morte uma espécie de hipermorte 11.

Outro vocábulo que vem sendo utilizado por alguns autores é a ortotanásia, que pode ser demarcada como a morte no seu tempo certo, sem os tratamentos desproporcionais (distaná- sia) e sem abreviação do processo de morrer (eutanásia) 32,43,44. A pergunta que fica, em relação ao termo ortotanásia, se dirige ao significado deste tempo certo para morrer. Com efeito, quem poderia determiná-lo (a não ser talvez o próprio titular da vida em questão) considerando um contexto no qual há possibilidade quase inesgotável de se prolongar a vida? Em outros termos, haveria um verdadeiro limite entre a eutanásia passiva - não intervir e deixar de fato morrer - e a dita ortotanásia - deixar morrer no momento aparentemente certo? A distinção se mostra conceitualmente precária, por vezes impossível de ser estabelecida afinal, não entubar um paciente com uma neoplasia em fase terminal, ou seja, negar-lhe a possibilidade de se manter vivo, seria deixar a morte chegar no tempo certo ou praticar de fato a eutanásia passiva? Ou, ainda mais, os dois termos seriam ao mesmo tempo semântica e pragmaticamente sinônimos, isto é, equivalentes do ponto do sentido e daquele das práticas surtindo o mesmo tipo de efeito? Por conta destas inconsistências, torna-se pouco útil empregar a expressão ortotanásia no debate bioético sobre a finitude, na medida em que traz mais problemas do que soluções.

A palavra mistanásia, por sua vez, vem sendo proposta com o sentido de "morte miserável e dolorosa fora e antes do seu tempo" 43 (p. 188), incluindo: (1) a falta de acesso às condições mínimas de vida; (2) a omissão de socorro à multidão de doentes à margem dos sistemas de saúde mundo afora; (3) as conseqüências dos diferentes tipos de erros médicos; e (4) as práticas de eliminação dos indesejados, como o ocorrido no período do Terceiro Reich 43 . O grande leque de circunstâncias alcunhadas como mistanásia, a eventual sobreposição com a idéia de distanásia e as dificuldades inerentes à determinação de um passamento ocorrido fora do seu momento correto - afinal, sempre é tempo para morrer... - tornam mistanásia um conceito deveras problemático nas discussões ora entabuladas.

Feitas estas considerações acerca do problema semântico e de suas implicações pragmáticas, impõe-se a discussão do problema moral pertinente, ou seja, dos argumentos pró e contra a eutanásia, questão bioética que se pode chamar de controvérsia sobre a moralidade da eutanásia, como será apresentada a seguir.

\section{Argumentos contra}

A eutanásia é uma temática sujeita a vários questionamentos, alguns de indubitável legitimidade. Os mais importantes argumentos con- 
trários à sua realização centram-se no princípio da sacralidade da vida e no argumento da "ladeira escorregadia" ou slippery slope.

- Princípio da sacralidade da vida

Segundo esta premissa absoluta, a vida consiste em um bem - concessão da divindade ou manifestação de um finalismo intrínseco da natureza -, possuindo assim um estatuto sagrado - isto é, incomensurável do ponto de vista de todos os "cálculos" que possam, eventualmente, ser feitos sobre ela -, não podendo ser interrompida, nem mesmo por expressa vontade de seu detentor. Uma outra leitura possível da sacralidade ganha força na afirmação de que a vida é sempre digna de ser vivida, ou seja, estar vivo é sempre um bem, independente das condições em que a existência se apresente. Apesar de ser considerada uma das mais contundentes objeções à eutanásia - mormente nas éticas cristãs e na tradição hipocrática 45 -, uma questão se impõe de pronto: se a vida é realmente um bem, quem seria o mais competente para julgar esta "beatitude"? Não recairia tal prerrogativa sobre o próprio titular da existência? Afirmar de maneira genérica e peremptória que a vida é algo bom em si mesmo - para além do truísmo de considerá-la como condição necessária para se poder falar em suas eventuais qualidades ou não - com base na ótica de algumas pessoas não implicadas nas vidas particulares em exame, é extremamente perigoso, em concordância com muitas das reflexões críticas, consubstanciadas ao longo do século XX e dirigidas à obsessão pelas generalidades, pois, afinal, a detecção de semelhanças não pressupõe a existência de gerais 46 . Ademais, a própria assertiva acerca da vida como um bem em si mesmo pode ser questionada, como vem sendo feito na história do pensamento, desde os seus primórdios - veja-se os órficos, Empédocles de Agrigento, Søren Kierkgaard e Emil Cioran, dentre outros $47,48,49,50$.

- Argumento de slippery slope

Traduzível em português como ladeira escorregadia, pretende justificar que não devem ser feitas "concessões" aparentemente inócuas em temas controversos, sob pena de se abrir o precedente para atitudes de inequívoco malefício 51. Oposições alicerçadas no argumento "escorregadio" incluiriam: (1) a potencial desconfiança - e subseqüente desgaste - na relação médico-paciente; (2) a possibilidade de atos não inspirados em fins altruístas, mas motivados por outras razões (por exemplo, questões de heranças, pensões, seguros de vida e outras); (3) a ocorrência de pressão psíquica por exemplo, o pensamento, pelo enfermo, de que sua condição é um verdadeiro "estorvo" para os familiares -, que poderia deixar os pacientes, cuja morte se aproxima, sem perspectiva outra que não a "eutanásia”, de fato não desejada e, portanto, de alguma forma imposta por razões circunstanciais; e (4) a erosão definitiva do respeito à vida humana, tomando-se como base o recorrente exemplo do nazismo 33,52. Entretanto, nem sempre tal preocupação poderá ser fundamentada, uma vez que o mau uso (ou o abuso) de algo não contra-indica, em termos absolutos, o seu uso (abusus non tollit usus): "se em alguns casos, especialíssimos, pode ser justificado e até mesmo necessário desrespeitar um sinal vermelho, essa não é uma boa razão para eliminar o sistema de circulação de veículos baseado em sinais luminosos, nem para atenuar o rigor das regras de trânsito, prevendo possíveis exceções, que ficariam sujeitas inevitavelmente a abusos perigosos" 52 (p. 396).

De outro modo, análises minuciosas do argumento da ladeira escorregadia acabaram por demonstrar que, em última análise, o impedimento refere-se muito mais à inexorabilidade do fenecer do que, propriamente, ao fato de "deslizar” em direção a um mau uso da prática 52 .

\section{Argumentos pró}

Dois são os principais pontos de apoio dos defensores da eutanásia: os princípios da qualidade de vida e da autonomia pessoal.

- Princípio da qualidade de vida

É um princípio geral, ou metaprincípio, com validade prima facie - ou seja, um princípio que subsume lógica e semanticamente outros princípios, mas que só é aplicável sob determinadas circunstâncias, sendo destituído, portanto, de um valor universal e inatacável que afirma também a existência de um valor para a vida, mas aplicável, tão somente, se esta é provida de um certo número e grau de qualidades histórica e socioculturalmente construídas e aceitas pelo titular de uma vida particu$\operatorname{lar} 45$. Assim, a existência teria realmente um valor condicionado às percepções e concepções das sociedades secularizadas, laicas e plurais, em um tempo próprio. A contraposição ao princípio da qualidade de vida tem a ver com a possibilidade de atos absurdos, geradores de sofrimentos insuportáveis, tão somente para sustentar uma (sobre)vida que pode ser mais um castigo do que uma dádiva 32 .

Sacralidade e qualidade de vida têm sido tratadas como princípios antagônicos e inconciliáveis. A despeito desta aporia, pode-se tentar uma composição entre ambos - não simplesmente dialética (no sentido hegeliano), mas sim no âmbito mais amplo do método da com- 
plexidade - segundo a qual estabelecer-se-ia uma nova relação princípio da sacralidade da vida e/ou princípio da qualidade de vida - ao invés de princípio da sacralidade da vida versus princípio da qualidade de vida -, integrando tanto as conexões de simpatia quanto aquelas de antipatia entre eles, em uma unidade discursiva de segunda ordem 5,45. Resultaria, assim, uma unidade que incorpora as tensões e ambigüidades em termos de relação de relações (e não mais unicamente de objetos).

Uma das questões mais íntimas em relação à qualidade de vida é determinar-se qual o real significado de uma vida que vale a pena ser vivida e para quem deve ser dada a prerrogativa em decidir sobre tal significação. Na esteira da herança kantiana - segundo a qual um ato genuinamente moral deve ser concebido no pleno exercício da liberdade do sujeito ético 53 cabe sempre admitir que o principal interessado em viver deve ter a preeminência, ou prioridade léxica, em decidir sobre sua vida e sua morte. Tal colocação remete, quase instantaneamente, à questão da autonomia pessoal, considerado o mais importante princípio para legitimar a eutanásia 38,54 , pelo menos se pensada no contexto das sociedades complexas liberais e democráticas contemporâneas, nas quais existem, como esteio, âmbitos de pertinência distintos relativos a ordens legítimas, também distintas - como aquelas do individual e do coletivo - e que não podem ser esquecidas, sob o risco de sobrevir a dissolução de um convívio razoável entre indivíduos neste tipo de sociedades.

- Autonomia

O termo, de origem grega - $\alpha v \tau$ ovo $\mu \iota \alpha$, de $\alpha v \tau o \varsigma$ = próprio, e vouos $=$ leis - remete à idéia de autogoverno, tendo sido empregado, historicamente, no seio da democracia grega para indicar as formas de governo autárquicas - isto é, a $\pi \mathrm{o} \lambda \iota \varsigma$ (pólis) 55 -, de fato a primeira forma consensualmente conhecida de democracia no Ocidente, ainda que incompleta por não contemplar escravos e mulheres. A partir da Modernidade, isto é, do movimento cultural e social iniciado pela Renascença, e que trouxe a idéia de indivíduo ao cenário da reflexão filosófica e política, o conceito de autonomia passa a se aplicar ao indivíduo - um necessário "produto" da modernidade burguesa e protestante na ponderação de Weber 56 -, alcançando uma formulação moral sistemática com a Fundamentação da Metafísica dos Costumes de Kant 53,55.

Pode-se definir como autônomo o indivíduo que "(...) age livremente de acordo com um plano escolhido por ele mesmo, da mesma for- ma que um governo independente administra seu território e define suas políticas" 19 (p. 138).

Com base neste pressuposto, os autores que "defendem" a eutanásia apontam para a necessidade de que seja respeitada a liberdade de escolha do homem que padece, isto é, sua competência em decidir, autonomamente, aquilo que considera importante para viver sua vida, incluindo nesta vivência o processo de morrer, de acordo com seus valores e interesses legítimos. Deste modo, com raízes fincadas no espírito helênico e florescimento manifesto na $A u f$ klärung (Iluminismo, literalmente "esclarecimento"), a autonomia pressupõe que cada indivíduo tem o direito de dispor de sua vida da maneira que melhor lhe aprouver, optando pela morte no exaurir de suas forças, ou seja, quando sua própria existência se tornar subjetivamente insuportável 38.

Deslocar-se-ia, assim, o debate bioético da finitude para a pergunta - genuinamente filosófica - sobre o alcance da autonomia do próprio interessado, encarnada na decisão de não permanecer em um martírio que não o conduzirá a lugar algum 57 ou, então, de continuar padecendo, não por uma decisão tomada por outrem, mas sim, por uma opção pessoal, que pode até ser a de se submeter, por boas razões, à imposição de um outro, mas que neste caso, se torna o Outro.

A despeito de sua eficácia teórica na argumentação bioética sobre o fim da vida - na medida em que contempla vários dos aspectos fundamentais em relação à eticidade, ou não, da eutanásia -, a idéia de autonomia apresenta uma série de problemas, os quais inviabilizariam seu uso de forma irrestrita, podendo-se mencionar: (1) a possibilidade, sempre real, de que haja dificuldade para a compreensão plena de aspectos da realidade, o que representa um genuíno "empecilho" para o exercício da autonomia, sobretudo se é colocado em foco um país - como o Brasil - no qual a maior parte da população não tem acesso à educação necessária ao exercício da cidadania e do livre direito de optar pelas melhores alternativas para a sua própria existência; (2) a impossibilidade lógica de se constituir um nomos particular, a partir de um indivíduo supostamente capaz de legiferar em nome de seus interesses, sem a necessária dialética estabelecida com um outro de si, uma vez que a tomada de decisões só é levada a cabo no âmbito de coordenadas socialmente determinadas por esta dialética; (3) a probabilidade, à luz da bioética principialista - calcada nos princípios de autonomia, jus tiça, beneficência e não-maleficência, ou outros de que sempre é factível a existência de confli- 
tos entre os princípios em pauta; (4) a existência de uma assimetria contingente nas relações entre profissionais de saúde e pacientes, devido às inegáveis competências diferentes entre quem pede ajuda e quem, supostamente, pode atender tal pedido e que pode, em inúmeras oportunidades, tornar inviável a aplicação do princípio, pela influência incontornável exercida por aquele que cuida 9,55,57.

Consideradas tais dificuldades, a grande indagação seria então: "como propiciar um contexto favorável à liberdade do homem no sentido de seu empoderamento de fato?". Com efeito, tal questionamento se delineia como um dos grandes desafios a serem enfrentados, no futuro, pelo Übermensch - o sobre-homem nietzschiano - o qual, de acordo com uma interpretação "pós-moderna” de Vattimo, deve ser entendido, sobretudo, como aquele que tenta ir para além de seus limites pessoais, e não como alguém capaz de exercer o poder sobre os demais 58 .

\section{Há novos horizontes para o debate? -} à guisa de (in)conclusão

A discussão, do modo como foi encaminhada até o presente momento, almejou a ordenação dos principais matizes que se combinam no debate moral sobre a eutanásia, podendo-se tomar, como analogia, o movimento do $\chi \alpha o s$ (caos, no sentido da "desordem" primordial) para o кобно (cosmo, no sentido de ordem), cantado por Hesíodo na Teogonia 59.

Como se tornou paulatinamente perceptível, os princípios da autonomia e da sacralidade da vida são os grandes pilares daqueles que se põem a favor e contra a eutanásia, respectivamente. Sem embargo, todas as colocações são passíveis de contestação, instaurando, assim, a necessidade de compor diferentes ordens de discurso - engendradas nas díspares tradições de pensamento - em um sistema complexo que permita a tomada de decisões, por vezes urgentes, em se tratando de pessoas acossadas pelos mais vis padecimentos.

Baseado nestas considerações, uma das interseções que se anuncia como promissora na elaboração dos aspectos conflituosos da eutanásia é, justamente, a de tomar entre os referenciais a atitude daqueles que se dispõem a executar o ato, abrindo-se a perspectiva para se colocar o problema da compaixão.

As grandes tradições morais que se fundam na compaixão são a cristã e a budista - ainda que possam ser encontrados elementos compassivos no hinduísmo, no islamismo e no judaísmo 60. Entretanto, se no cristianismo o sen- tido é de tomar para si, compartilhar, o sofrimento do outro 61 - do latim compati $=$ sofrer com, lembrando-se que, em grego, $\pi \alpha \theta$ os ( $p a ́$ thos) significa capacidade de sentir, sentimento profundo, afeto arrebatador -, na ética budista, apropriada pela filosofia ocidental no pensamento de Schopenhauer - na verdade, sua principal "influência oriental” foi recebida dos Upanixades hindus 62,63 -, a dimensão evocada por Karuna (compaixão, em sânscrito) é muito mais de acolhimento da angústia alheia: “compaixão significa oferecer morada às pessoas, abrir as portas até então fechadas para elas, perguntar mais que responder. Significa tornar-se altamente sensível à situação e aos sentimentos da outra pessoa. Significa ouvir com todo o seu ser e dar, se for possível, o que seja relevante e apropriado para o relacionamento, não o avaliando com julgamentos próprios" 64 (p. 51).

Tal acolhida pressupõe o não-julgamento do outro, mas sim, e tão somente, sua aceitação, o amparo de sua condição de vivente 60 . Se, conforme o discutido, o conceito de eutanásia pressupõe, de modo inequívoco, a existência de um lídimo estofo misericordioso, cabe ao profissional que cuida do enfermo, inserido no processo de morrer, o respeito a este seu momento elegíaco, recebendo-o e dispondo-se a atender seu desejo de morrer, sem julgá-lo, nem tomar arbitrariamente decisões tão importantes em seu lugar. Ademais, a compaixão, enquanto acolhimento - recepção daquele que sofre em seu próprio âmago -, permite uma fecunda articulação entre os princípios e argumentos morais acerca do fim da vida, compondo: (1) $s a$ cralidade da vida, (2) qualidade de vida e (3) autonomia, além de superar o (4) argumento do slippery slope.

De fato, a vida de um homem submetido a excruciante padecimento não deixa de ser $s a$ grada - pondo-se de lado os dogmatismos cegos e os fundamentalismos - pela decisão autônoma, por parte daquele que sofre, de se pôr um fim ao seu curso. Neste caso, a própria condição de se admitir, em meio a um padecimento incurável e intratável, que já não vale a pena prosseguir, demonstra, em certo sentido, que o doente atribui alto valor à sua própria vida, não desejando profaná-la ao permitir que ela se esvaia em dias e noites de martírios sem fim. Morrer, neste caso, pode significar também uma clara demonstração de apreço pela própria existência, situando-a em uma dimensão beatífica. E, ainda, se este mesmo homem é amparado - e, por que não, protegido - no sentido de se facultar sua inquebrantável disposição para o ocaso, não se corre o risco de estender, escorregar, indevidamente para situações obscuras 
e danosas em relação à prática da eutanásia, uma vez que a palavra daquele que sofre, o titular da vida, será sempre a última fronteira.

É bem verdade que esta é apenas uma breve digressão sobre um elemento de irrefutável alcance no debate ético e bioético sobre o fim da vida, a compaixão, que vem sendo pouco prestigiada nas reflexões contemporâneas. Integrá-la aos demais fios que compõem o grande tecido da eutanásia é uma forma de olhar e acolher o homem que morre, um genuíno ato

\section{Resumo}

A despeito das grandes discussões hodiernas sobre a eutanásia, permanecem ainda muitos pontos em aberto, aparentemente insolúveis, aguardando que um melhor tratamento conceitual seja desenvolvido. Neste âmbito podem ser incluídos os "preconceitos e fundamentalismos" em relação ao tema - a eutanásia ainda é vista como tabu em boa parte da sociedade, especificamente no caso do Brasil-, as imprecisões semânticas do vocábulo e as acérrimas tensões argumentativas em torno do tema - levando-se em consideração os princípios da sacralidade da vida, da qualidade de vida e da autonomia e o argumento da assim chamada "ladeira escorregadia" ou slippery slope. Compor o horizonte de indagação acerca da eutanásia, partindo dos antecedentes históricos em direção a um melhor equacionamento do problema - e delimitação de perspectivas vindouras necessárias à sua melhor compreensão - é, pois, o objetivo do presente ensaio.

Eutanásia; Bioética; Saúde Pública

\section{Colaboradores}

R. Siqueira-Batista e F. R. Schramm conceberam juntos a estrutura do presente ensaio; o primeiro autor colaborou preponderantemente nas seções Conceitos Fundamentais: Em Busca de Rigor e Há Novos Horizontes Para o Debate? - À Guisa de (In)conclusão, e o segundo para a argumentação (pró e contra) em torno da eutanásia. de fraternidade, permitindo-lhe, quiçá, a restituição da prerrogativa de sonhar com seus melhores dias de outrora, com o esfumar do martírio, com o descerrar das cortinas da existência, tão belamente escrito por Shakespeare 65 (p. 97): "morrer é dormir. Nada mais. E por um sonho, diremos, as aflições se acabarão e as dores sem número, patrimônio da nossa débil natureza. Isto é o fim que deveríamos solicitar com ânsia. Morrer é dormir... e talvez sonhar".

\section{Referências}

1. Kottow M. Introducción a la bioética. Santiago: Editorial Universitária; 1995.

2. Heidegger M. Ensaios e conferências. Petrópolis: Editora Vozes; 2002.

3. Jaeger W. Paidéia: a formação do homem grego. São Paulo: Martins Fontes Editora; 1995.

4. Kant I. Crítica da razão pura. São Paulo: Abril Cultural; 1980.

5. Schramm FR. A terceira margem da saúde. Brasília: Editora UnB; 1996.

6. Hershenov D. The problematic role of 'irreversibility' in the definition of death. Bioethics 2003; 17:89-100.

7. Schramm FR. A questão da definição da morte na eutanásia e no suicídio assistido. Mundo Saúde 2002; 26:178-83.

8. Camus A. Essais (le mythe de sisyphe). Paris: Gallimard; 1965.

9. Siqueira-Batista R, Schramm FR. Eutanásia: pelas veredas da morte e da autonomia. Ciênc Saúde Coletiva 2004; 9:31-41.

10. Deleuze G. Conversações. São Paulo: Editora 34; 1992.

11. Pessini L. Distanásia: até quando prolongar a vida? São Paulo: Editora São Camilo/Edições Loyola; 2001.

12. Suetônio. A vida dos doze césares. 2a Ed. São Paulo: Editora Prestígio; 2002.

13. Siqueira-Batista R, Schramm FR. A filosofia de Platão e o debate bioético sobre o fim da vida: interseções no campo da Saúde Pública. Cad Saúde Pública 2004; 20:855-65.

14. Alexander L. Medical science under dicatorship. N Engl J Med 1949; 241:39-47.

15. Singer P. Vida ética. Rio de Janeiro: Ediouro; 2002.

16. Almeida JLT, Schramm FR. Transição paradigmática, metamorfose da ética médica e emergenciada bioética? Cad Saúde Pública 1999; 15 Suppl 1:15-25. 
17. Mori M. A bioética: sua natureza e história. Humanidades 1994; 9:333-41.

18 Veille F. Vincent Humbert. "Je vous demande le droit de mourir". Neuilly-sur-Seine: Michel Lafon; 2003.

19. Beauchamp TL, Childress JF. Princípios de ética biomédica. 4a ed. São Paulo: Edições Loyola; 2002.

20. Anonimous. It's over, Debbie. JAMA 1988; 259: 2094-8.

21. McCarrick PM. Ethics committees in hospitals. Kennedy Inst Ethics J 1992; 2:285-306.

22. Quill TE. Death and dignity: a case of individualized decision making. N Engl J Med 1991; 324:691-4.

23. Lachs J. Dying old as a social problem. In: McGee G, editor. Pragmatic bioethics. Nashville/London: Vanderbilt University Press; 1994. p. 194-203.

24. Schramm FR. A difícil dialética entre economia e ética. Rev Bras Edu Méd 2000; 24:77-81.

25. Engelhardt DV. La eutanasia entre el acortameineto de la vida y el apoyo a morir: experiencias del pasado, retos del presente. Acta Bioética 2002; 8:55-66.

26. Sá MFF. Direito de morrer: eutanásia, suicídio assistido. Belo Horizonte: Editora Del Rey; 2001.

27. Dodge REF. Eutanásia - aspectos jurídicos. Bioética 1999; 7:113-20.

28. Jesus DE. Código penal anotado. 5ạ Ed. São Paulo: Editora Saraiva; 1995.

29. Prendergast TJ, Claessens MT, Luce JM. A national survey of end-of-life care for critically ill patients. Am J Respir Crit Care Med 1998; 158:1163-7.

30. Siqueira-Batista R, Siqueira-Batista R. De como filosofar é aprender a morrer. O pensamento de Michel de Montaigne como pressuposto na discussão sobre a morte e o processo de morrer na prática médica. Cad Saúde Coletiva 2002; 10:9-18.

31. Souza MTM, Lemonica L. Paciente terminal e médico capacitado: parceria pela qualidade de vida. Bioética 2002; 11:83-100.

32. Horta MP. Eutanásia - problemas éticos da morte e do morrer. Bioética 1999; 7:27-34.

33. Lepargneur H. Bioética da eutanásia: argumentos éticos em torno da eutanásia. Bioética 1999; 7 : 41-8.

34. Littré E. Dictionnaire de médecine. 21a Ed. Paris: Balliere; 1908.

35. Neukamp F. Zum problem der euthanasie. Der Gerichtssaal 1937; 109:403.

36. Kuhse H. La eutanásia. In: Singer P, editor. Compêndio de ética. Madrid: Trotta; 1995. p. 405-16.

37. Sacred Congregation for the Doctrine of the Faith. Declaration on euthanasia. Vatican City: Sacred Congregation for the Doctrine of the Faith; 1980.

38. Schramm FR. Por qué la definición de muerte no sirve para legitimar moralmente la eutanasia y el suicidio asistido? Perspectivas Bioéticas 2001; 6: 43-54.

39. Singer P. Ética prática. 2ạ Ed. São Paulo: Martins Fontes Editora; 1998.

40. De Blois J, Norris P, O'Rourke K. A primer for health care ethics. Washington DC: Georgentown University Press; 1995.

41. Pellizzari EML, Almeida RA. Suicídio: a metáfora de Dorian Gray. J Bras Psiquiatr 2001; 50:69-76.

42. Siqueira-Batista R. A ressurreição de Frankenstein: uma metáfora das UTIs contemporâneas. I
Congresso de Bioética do Estado do Rio de Janeiro. Rio de Janeiro: Editora Fiocruz; no prelo.

43. Martin LM. Eutanásia e distanásia. In: Costa SIF Oselka G, Garrafa V, organizadores. Iniciação à bioética. Brasília: Conselho Federal de Medicina; 1998. p 171-92.

44. Piva JP, Carvalho PRA. Considerações éticas nos cuidados médicos do paciente terminal. Bioética 1993; 1:129-39.

45. Schramm FR. Vida: sacralidade e/ou qualidade? Cadernos Atualidade em Debate 1995; 34:44-69.

46. Wittgenstein L. Tratado lógico-filosófico e investigações filosóficas. Lisboa: Fundação Calouste Gulbenkian; 1989.

47. Siqueira-Batista R. Deuses e homens: mito, filosofia e medicina na Grécia antiga. São Paulo: Landy Editora; 2003.

48. Kirk GS, Raven JE, Schofield M. Os filósofos présocráticos. Lisboa: Fundação Calouste Gulbenkian; 1994.

49. Cioran E. Sur les cimes de desespoir. Paris: Gallimard; 1995.

50. Kierkegaard S. Doença até a morte. São Paulo: Abril Cultural; 1979.

51. Schauer F. Slippery slopes. Harv Law Rev 1985; 99:361-83.

52. Neri D. A eutanásia em uma perspectiva leiga. Humanidades 1994; 9:388-97.

53. Kant I. Fundamentação da metafísica dos costumes. Lisboa: Edições 70; 1960.

54. Donkin A. Autonomy, interdependence, and assisted suicide. Bioethics 2001; 14:187-204.

55. Schramm FR. A autonomia difícil. Bioética 1998; 6:27-37.

56. Weber M. Die protestantische ethik und der geist des kapitalismus. Gesammelte aufsätze zur religionsoziologie. v. I. Suhrkamp: Frankfurt a/Main; 1973.

57. Kottow M. Enseñando las paradojas de la autonomía. Rev Bras Edu Méd 2000; 24:40-5.

58. Vattimo G. Al di là del soggeto. Nietzsche, Heidegger e l'ermeneutica. Milano: Feltrinelli; 1981.

59. Hesíodo. Teogonia: a origem dos deuses. $3 a$ Ed. São Paulo: Iluminuras; 1995.

60. Boff L. Saber cuidar: ética do humano, compaixão pela Terra. 8a Ed. Petrópolis: Editora Vozes; 2002.

61. Santo Agostinho. Confissões. São Paulo: Nova Cultural; 2000.

62. Janaway C. Schopenhauer. São Paulo: Edições Loyola; 2003.

63. Schopenhauer A. Sobre o fundamento da moral. São Paulo: Martins Fontes Editora; 2001.

64. Brandon D. Ajuda pelo zen-budismo. São Paulo: Editora Pensamento; 1976.

65. Shakespeare W. Hamlet. Rio de Janeiro: Editora Objetiva; 2003.

Recebido em 27/Mai/2004

Versão final reapresentada em 25/Ago/2004

Aprovado em 31/Ago/2004 